\title{
The Impact of Internet Real Estate Intermediary Platform on the Real Estate Market
}

\section{_- Empirical Evidence from the Natural Experiment Shock of the Central Bank Interest Rate Cut Policy}

\author{
Wenzhan Zhang \\ Hunter Information Technology \\ Beijing Zhuge House \\ Beijing, China \\ vincent@zhuge.com
}

\author{
Dongmei Guo ${ }^{1}$ \\ School of Economics \\ Central University of Finance and Economics \\ Beijing, China \\ guodongmeicufe@163.com
}

\author{
Shaofei Chen \\ School of Economics \\ Central University of Finance and Economics \\ Beijing, China \\ chensf2511@163.com
}

\author{
Bing $L i$ \\ School of International Trade and Economics \\ Central University of Finance and Economics \\ Beijing, China \\ lukeice2000@163.com
}

\begin{abstract}
The real estate industry not only plays an important role in the economy development of China, but also receives widespread attention from public as it involves the vital interests of every family. High housing prices and violent fluctuations are often criticized as obstacles to the further economic development. In many product markets, it is found that e-commerce platforms have significant advantages in information symmetry and transparency. This helps to stabilize prices and reduce volatility. However, there is no research specifically on the impact of e-commerce platforms on the real estate market. This paper explores the impact of the emerging Internet real estate intermediary platform on the real estate market based on difference-in-difference model(DID). This paper analyzes the real estate transactions data in Beijing from 2015 to 2016 and the interest rate cut policy of People's Bank of China in Octorber 2015. The results show that compared with the traditional intermediary, the Internet trading platform has significantly reduced the housing price increase and transaction fluctuations after the policy shock. Taken into account the characteristic differences in the property of the two trading methods, we use the PSM-DID method to reanalyze the data.And We did not found any difference about the results .
\end{abstract}

Keywords-real estate market; trading volatility; internet intermediary; interest rate cut of People's Bank of China

\section{CCS CONCEPTS}

- Social and professional topics Information system economics - Applied computing Electronic commerce • Applied computing Economics

\section{INTRODUCTION}

In recent years, the impact of the real estate market on the economic development of China has become increasingly

Permission to make digital or hard copies of all or part of this work for personal or classroom use is granted without fee provided that copies are not made or distributed for profit or commercial advantage and that copies bear this notice and the full citation on the first page. Copyrights for components of this work owned by others than ACM must be honored. Abstracting with credit is permitted. To copy otherwise, or republish, to post on servers or to redistribute to lists, requires prior specific permission and/or a fee. Request permissions from Permissions@acm.org.ICCSE'19, October 18-21, 2019, Jinan, China 2019 Association for Computing Machinery.ACM ISBN 978-1-4503-7640-2/19/10 $\$ \$ 15.00$ important. At present, the growth rate of real estate investment in China is far higher than that of fixed asset investment and GDP. In particular, housing prices have continued to rise rapidly in recent years. How to balance the housing prices in a reasonable and stable range directly affects China's overall development. And this also effects social harmony and stability.

After the financial crisis in 2008, housing prices has always been affected by the government control policies on housing price at all levels. This has also caused a large degree of fluctuations in China's real estate in recent years. Considering the time lag of macroeconomic policies, frequent fluctuations in the real estate market will have negative impact on the real estate market and even the national economy. How to reduce the volatility of the real estate market and avoid the short-term imbalance have become an important issue. This will have positive effect on the real estate market and even the national economy.

At present, the types of real estate agencies in China are mainly divided into two categories. One is a real estate service company with an advantage of offline agency, such as Lianjia.com and 5i5j.com. The other is the newly developed Internet real estate intermediary platform represented by soufang.com and FANG.com. This kind of real estate agencies has the information display function based on the information aggregation platform. They also introduces payment and transaction functions on the platform to form a complete $\mathrm{O} 2 \mathrm{O}$ closed loop. Different from the traditional intermediary between the buyer and the seller, the Internet has significant advantages in information symmetry and transparency. The custom can reduce the impact of real estate agents on prices in housing transactions by timely obtaining other transaction information. To a certain extent, the custom can gain positive postion in the the transaction price. When the real estate industry is compatible with the Internet, it will further promote the separation of real estate agents and real estate transactions. This is the optimum results for buyers or sellers under certain conditions (Michael Nwogugu, 2007). Therefore, it is not difficult to predict that in dealing with macroeconomic policy shocks, compared with traditional intermediaries, 
Internet real estate intermediary platforms can be less susceptible on the policy fluctuations and price distortion of the real estate. This paper will study the transaction data of these two intermediaries from this perspective, and explore the differences in the degree of volatility between the two intermediaries in response to policy shocks.

\section{LITERATURE REVIEW}

In the research of the real estate market, it is widely believed that intermediaries play a vital role in the transaction process. As they have the information advantages.So it is common to study many phenomena in the real estate market in the view of intermediaries. Bagnoli and Khanna (1991) pointed out that the intermediary reduce the buyer's search cost and increase the possibility of buying the house. If the increase in the selling price due to the intermediary is lower than the payment of seller, the buyer and the seller will all benefit from the trade; Spulber (1999) described the existence and functions of real estate market brokers; Rutherford, Springer and Yavas $(2001,2004)$ studied the role of real estate agents in trading. Compared with the owner of the house without selling through the broker, they figure out that brokers can help sellers sell their houses at a higher price with less time cost. Compared with sellers, brokers have the information advantage in the real estate trade process,. This cause a lot of potential problems. When enough intermediaries try to increase the transaction price for higher commissions based on this information advantage, it will cause price distortion in the real estate market. Especially with the shock of macroeconomic policies, this price distortion will become more apparent and result in unnecessary fluctuations in the overall market. Clayton (1996) pointed out that for mid-priced houses, the closer the final price is to the starting price, the shorter the time to hang in the market and wait until the sale, but for low-priced and highpriced houses, there is no significant relationship between the two; on the other hand, the length of time from hanging in the market to the time of sale does not depend on the physical and location attributes of the house, but on the market conditions at the time of sale; At present, domestic scholars' research on the real estate market, especially the volatility of the real estate market, mainly focuses on the macro policy level. Yang Liu, Li $\mathrm{Li}$, and $\mathrm{Wu}$ Ting (2016) proceeded from the four categories of economic growth, inflation, financial environment and monetary policy on the expected impact of the real estate market, and built a Keynesian model containing the real estate market to explain the fluctuations of China's housing market; Guo Kesha (2014) combined the volatility of real estate in China in recent years with the international situation, explored the trend of real estate volatility in China and predicted the future trend and how the government adjusts.

In the study of Internet technology on the real estate market, Michael Nwogugu (2007) pointed out that in the process of real estate trading, the role of the intermediary is crucial, but under some certain conditions, no intermediary is the best result for the buyer or seller. With the advancement of the times, the increase in Internet convenience has made this possibility gradually increasing and may become the most common form of relationship. HAROLD GEE (2010) studied the use of $\mathrm{B} 2 \mathrm{C}$ real estate network resources and its impact on consumers. The gradual enrichment of B2C real estate network resources reflected a series of prominent features, especially for companies with their own real estate resources. It made the value of the house assets that can only be secretly shared between real estate agents gradually open and transparent, thus created a new business model. The Internet was also gradually changing the way in which real estate agents negotiate business with buyers and sellers, so that the dominant position in the negotiations gradually shifted from agents to buyers and sellers. The author pointed out that further research was needed to determine whether the Internet created an effective market for residential real estate transactions and learnt more about the evolution of the future roles of brokers and agents; Raymond Y.C. Tse and James R. Webb (2002) used regression models to empirically study the impact of information technology on Hong Kong's real estate brokerage industry to explore how information on the Internet affected real estate transactions and commissions. The results showed that the number of page views on real estate sales sites had a positive impact on the perperson transactions and commissions of the company's employees, but the elasticity was less than 1; In the domestic scholars' research on internet real estate.

In the research of the Internet market, domestic and foreign scholars have studied the impact of the macro level on the Internet market from the specific perspectives of overall Internet commerce development, international trade and financial markets. In the study of overall Internet business development, Jonathan D.Levin (2011) studied the characteristics of the Internet gradually becoming large-scale, rapid expansion of customers, and rapid changes in technology, and summarized the application of online advertising market and retail, financial and other economic theories in the field of e-commerce, such as the generalized second price bidding model (GSP) of the online auction platform, etc. At a specific industry level, Maggie X. Chen and Min Wu (2017) used Alibaba as an example to study the impact of the reputation mechanism of online platforms on import and export trade. The study pointed out that the improvement of reputation can significantly promote the growth of trade exports and had a significant sales distribution level. Michael Dinerstein, Liran Einav, Jonathan Levin, et al. (2014) proposed that although the cost of web search was low, the price dispersion still existed. They used different designs of eBay's product search interface to generate different effects of price dispersion. At the macro level, Jonas Hjort and Jonas Poulsen (2017) pointed out that the promotion of Internet use promoted the employment rate of all workers in low-employment countries in Africa, and created more employment opportunities, average income and wealth growth by analyzing employment data at the African company level. Hou Hanpo and He Mingwei (2010) pointed out that the resources of the Internet were characterized by technology, publicity and permeability. For the real economy, the Internet had created a new economic form and caused changes in traditional industries, resulting in a large number of projectbased virtual organizations. It improved the flexibility of regional resource allocation, changed the production organization form of traditional enterprises, improved the ability of enterprises to allocate resources, improved the sufficiency of information and reduced the transaction costs.

From the latest progress of the above three types of literature, we can find that on the one hand, there is no research on the "de-broker" trading method of online trading platform. 
On the other hand, there are many studies on the impact of the Internet on various aspects of the economy. Many scholars have conducted research on the Internet on the real estate market, but most of them have focused on the theoretical level. There are fewer scholars who have empirically studied the impact of the Internet on the real estate market, especially the Internet-based online real estate intermediary platform. This paper takes advantage of the 2015 central bank interest rate cut policy as an exogenous shock and empirically tests the impact of the Internet real estate intermediary platform on the real estate market.

\section{DATA}

This paper hopes to explore the impact of Internet trading platforms on the price changes of housing transactions in the face of policy shocks, so we select one of the most obvious policies on the impact of housing price fluctuations in recent years, which is the central bank's interest rate cut policy as a corresponding policy shock. In 2015, the central bank cut interest rates five times and experienced the five interest rate cuts. For example, the benchmark interest rate for commercial loans over 5 years has dropped from $6.15 \%$ at the end of 2014 to $4.9 \%$.

The central bank's five interest rate cuts policy not only creates a good monetary and financial environment for the adjustment of China's economic structure and stable and healthy economic development, but also greatly promotes the demand for home purchases in the real estate market in Beijing, the policy of the central bank to cut interest rates will have a significant positive impact on the transaction volume and transaction price of the Beijing real estate market. Since traditional real estate agents can earn a commission of $3 \%$ of the transaction price, in the case of severe information asymmetry, Rutherford, Springer and Yavas (2001, 2004) pointed out that in order to obtain higher commissions, ordinary real estate brokers were more motivated to push the two sides to trade at a higher price, but in the Internet intermediary platform, the price information was more transparent, and the possibility of artificially pushing up the price was reduced. In the same way, the policy shock broke the original equilibrium. When the information was asymmetric, the good news of the real estate market can be further amplified, resulting in more intense trading volatility. In the short term, it was assumed that the audience objects of different trading platforms were the same group, so the invisible features can be subtracted by differential, that is, the potential endogenous problem can be solved, thereby the impact of the Internet real estate intermediary platform on real estate transactions can be better measured.

Since the interest rate cut policy took place in 2015 , in order to take advantage of this policy as a shock, the housing transaction data taken in this paper was mainly taken from realtime transaction data from 2015 to 2016 in Beijing. The property transaction data in this article came from "zhuge.com" website the real estate search engine. This paper selects the transaction data of two representative intermediaries, LianJia and FangTianXia. In 2014, FangTianXia took its own transformation, joined the function of housing transactions, and developed its own sales and service functions through its large sales channels and resources. At the beginning of January 2015, FangTianXia second-hand house e-commerce group was formally established to carry out second-hand housing transaction business, and in the first half of 2015, it took the lead in Beijing, Shanghai and other cities. Different from real estate agencies, such as LianJia and ZhongYuan, which relied on the resource advantages established by a large number of offline stores and managers, SouFang.com reduced the brokerage fee by saving the expenses required by the traditional intermediary line, thereby reducing the cost of buying a house to attract consumers. However, due to its small market share and the company's competitive strategy, FangTianXia slid into a loss in the new and second-hand housing market, announced the transformation failure in 2017 and returned to the original open platform strategy.

In the real-time transaction data provided by the "zhuge.com", each transaction data included specific physical properties. These included: the transaction price per unit area of the house "a_price"(thousands per square meter); logarithm of housing area "In_area"; number of rooms "room"; number of halls "hall"; virtual variable of house orientation "toward", taking 1 when the house is facing south, the other is 0 ; dummy variables constructed to measure the floor where the house is located "median 、 tall", When the floor to which the house belongs is medium, median takes 1 and the others are 0 . When the floor to which the house belongs is high, the tall takes 1 and the others are 0 ; the total floor "topfloor"; the age of the house "age" and square of the age "age2". At the same time, each individual data also included the transaction date and the latitude and longitude data of the cell in which it was located. According to the latitude and longitude of the cell to which it belonged, this paper processed the data through arcgis software to calculate the geographic attribute elements of each real-time transaction data which included: dummy variable whether it is a key primary school district "school", if it is a key primary school district, we takes 1 and vice versa 0 ; numbers of popular reviews restaurants within $1 \mathrm{~km}$ "restaurant"; distance to the nearest McDonald's restaurant "McD"(meter); distance to the nearest subway station "subway"(meter); distance to the nearest top three hospital "hospital" (meter); dummy variable whether it is within five rings "five_circle", if it is within five rings, we takes 1 and vice versa 0 . In the end, this paper selected the housing transaction data from June 2015 to March 2016. After removing the invalid data, it contained about 110,000 transaction data, covering various urban areas in Beijing. See Table $\mid$ for descriptive statistics of the main variables.

From the comparison of the statistical data of the two trading institutions, compared with the LianJia, FangTianXia would sell higher housing area, more number of rooms and lower unit price when trading. The average transaction price difference between the two accounted for about $10.7 \%$ of the overall average. In addition, the housing age of FangTianXia was significantly lower than that of the LianJia. In the transaction data of FangTianXia, the proportion of school districts in key primary schools was relatively small compared with LianJia. There was no significant difference between the two in the distance from the subway station and the top three hospitals. 
In order to further explore the relationship between the transaction price of the two trading institutions and the policy shock, this paper is based on the monthly transaction data. This article uses the fifth interest rate cut by the central bank., that is, October 2015, as the $\mathrm{T}=0$ period and observes the trend of the unit price of the monthly trading data of the two trading institutions before and after the policy shock. The changes in the transaction prices of the two trading institutions from $\mathrm{T}-4$ period to $\mathrm{T}+5$ period are shown in Figure 1. It can be seen from this that the trading price of LianJia had been steadily rising, especially after the fifth interest rate cut by the central bank but the trading data of FangTianXia was always in the ups and downs. After the shock of the policy, it did not show a clear upward trend. To a certain extent, this shows that the Internet real estate intermediary platform has indeed affected the price increase in housing prices. This paper will further demonstrate this point through subsequent empirical research.

TABLE I. Statistics CHARACTERIZATION OF THE MAIN VARIABLES

\begin{tabular}{|c|c|c|c|c|c|c|c}
\hline Variables & Mean & $\begin{array}{c}\text { Standard } \\
\text { Error }\end{array}$ & Min & Max & Obs & \multicolumn{2}{|c}{ MangTian } \\
Xia & LianJia \\
\hline a_price & 3.9 & 2.1 & 0.05 & 134.6 & 109710 & 3.45 & 3.87 \\
\hline Area & 86.3 & 40.3 & 7 & 808 & 109710 & 94.0 & 86.0 \\
\hline Room & 2.0 & 0.84 & 0 & 9 & 109710 & 2.1 & 2.0 \\
\hline Hall & 1.2 & 0.6 & 0 & 9 & 109710 & 1.3 & 1.2 \\
\hline Toward & 0.27 & 0.44 & 0 & 1 & 109710 & 0.14 & 0.28 \\
\hline Median & 0.35 & 0.48 & 0 & 1 & 109710 & 0.33 & 0.36 \\
\hline Tall & 0.33 & 0.47 & 0 & 1 & 109710 & 0.38 & 0.32 \\
\hline Topfloor & 13.0 & 8.2 & 0 & 42 & 109710 & 13.2 & 13.0 \\
\hline Age & 18.0 & 21.6 & 0 & 116 & 109710 & 12.5 & 18.2 \\
\hline School & 0.03 & 0.17 & 0 & 1 & 109710 & 0.02 & 0.03 \\
\hline Restaurant & 1251 & 1080 & 0 & 6547 & 109710 & 1081 & 1258 \\
\hline McD & 1754 & 2564.5 & 24.7 & 117479 & 109710 & 1762 & 1754 \\
\hline Subway & 1508 & 2997 & 21.8 & 128360 & 109710 & 1574 & 1505 \\
\hline Hospital & 5173 & 6250 & 7.9 & 127824 & 109710 & 4962 & 5182 \\
\hline Five-circle & 0.5 & 0.5 & 0 & 1 & 109710 & 0.42 & 0.5 \\
\hline Agency & 0.04 & 0.19 & 0 & 1 & 109710 & 1.000 & 0 \\
\hline
\end{tabular}

Fig. 1. Example of a figure caption. (figure caption)

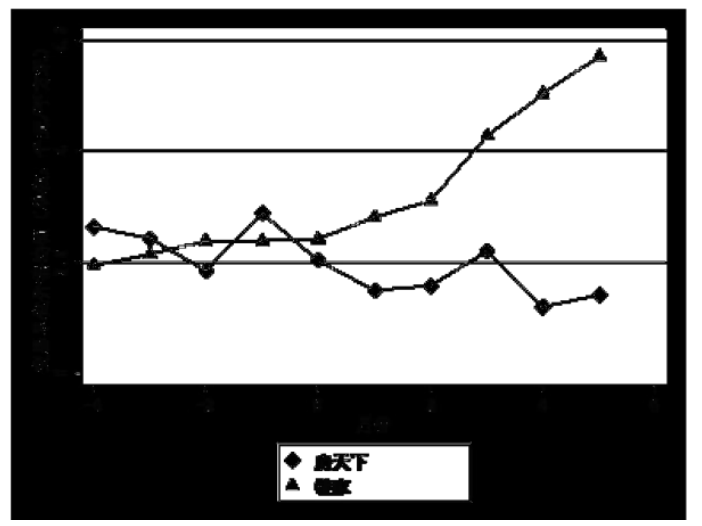

\section{METHOD OF BENCHMARK REGRESSION}

\section{A. The impact of Internet real estate intermediary platform on transaction price}

This paper takes the individual transaction data of the whole house as the research object, explores the influence of the Internet real estate intermediary platform on the transaction price of the house price and improves the validity of the model by using the simple least squares regression equation and controlling other variables. Therefore, we use the following regression equation (1).

$$
\text { a_price }=\beta_{10}+\beta_{1} X_{\mathrm{I}}+\beta_{2} L_{\mathrm{I}}+\beta_{3} \text { Agency } y_{1}+\beta_{4} M_{\mathrm{i}}+\beta_{5} D_{\mathrm{L}}+u_{\mathrm{i}} \quad \text { (1) }
$$

$\mathrm{X}$ is the physical property vector of the house, which specifically includes: ln_area 、 room 、 hall 、 toward . median 、 tall 、topfloor age age 2. L is the community location attribute vector of the house, which specifically includes: ln_subway 、 ln_hospital 、school. "Agency" is a dummy variable as an intermediary. When FangTianXia is used as an intermediary, "Agency" takes the value 1 and vice versa 0 . In addition, the paper also adds the monthly fixed effect $M_{i}$ of the trading time and the fixed effect $D_{i}$ of the urban area.Maintaining the Integrity of the Specifications.

In this paper, regression is performed according to the above regression equation. The regression results are shown in Table ||.Table || shows the impact of the Internet real estate intermediary platform on the transaction price of the house. Column (1), (2) and (3) all control the same variables to regress the overall transaction data. However, column (1) only adds the mediation variable, column (2) adds the physical attribute vector on the basis of column (1) and column (3) adds the community location attribute vector on the basis of column (2). The results of the three columns show that the coefficient of the intermediary variable is negative and significant, that is, compared with LianJia, FangTianXia's transaction price per unit area of the house is lower about 2340 yuan per square meter.

Many of the control variables in the regression also have a significant impact on the transaction price. The area of the house has a significant positive impact on the total price but has a significant negative impact on the unit price, that is, the larger the area, the lower the unit price of the house transaction. The coefficient of the number of bedrooms and the number of halls in the house are significantly positive and there is a clear positive relationship with the transaction price of the house. The distance to the subway station and the top three hospitals also have a significant negative impact on the transaction price and the effect of the distance to the subway station is higher than the distance to the top three hospitals. The positive effect of the variable of the school district of the key elementary school on the transaction price of the house is also extremely significant and its influence coefficient on the transaction price of the house is extremely large, which is also in line with the fact that the current school district's housing market premium is serious. 
TABLE II. THE IMPACT OF INTERNET REAL ESTATE INTERMEDIARY PlatForm ON HOUSING TRANSACTION PRICE

\begin{tabular}{|c|c|c|c|}
\hline Dependent Variable & $\begin{array}{c}\text { (1) } \\
\text { a_price }\end{array}$ & $\begin{array}{c}\text { (2) } \\
\text { a_price }\end{array}$ & $\begin{array}{c}\text { (3) } \\
\text { a_price }\end{array}$ \\
\hline Agency & $\begin{array}{c}-0.232 * * * \\
(0.057)\end{array}$ & $\begin{array}{c}-0.227 * * * \\
(0.019)\end{array}$ & $\begin{array}{c}-0.234 * * * \\
(0.018)\end{array}$ \\
\hline Ln_area & & $\begin{array}{c}-1.590 * * * \\
(0.067)\end{array}$ & $\begin{array}{c}-1.570 * * * \\
(0.067)\end{array}$ \\
\hline Room & & $\begin{array}{c}0.384 * * * \\
(0.016)\end{array}$ & $\begin{array}{c}0.371 * * * \\
(0.016)\end{array}$ \\
\hline Hall & & $\begin{array}{c}0.444 * * * \\
(0.020)\end{array}$ & $\begin{array}{c}0.453 * * * \\
(0.020)\end{array}$ \\
\hline Toward & & $\begin{array}{c}0.044 * * * \\
(0.013)\end{array}$ & $\begin{array}{c}0.033 * * \\
(0.013)\end{array}$ \\
\hline Median & & $\begin{array}{c}0.120 * * * \\
(0.012)\end{array}$ & $\begin{array}{c}0.125^{* * *} \\
(0.012)\end{array}$ \\
\hline Tall & & $\begin{array}{c}0.006 \\
(0.013)\end{array}$ & $\begin{array}{c}0.020 \\
(0.012)\end{array}$ \\
\hline Topfloor & & $\begin{array}{c}0.021 * * * \\
(0.001)\end{array}$ & $\begin{array}{c}0.021 * * * \\
(0.001)\end{array}$ \\
\hline Age & & $\begin{array}{c}0.001 \\
(0.001)\end{array}$ & $\begin{array}{c}-0.006 * * * \\
(0.001)\end{array}$ \\
\hline $\mathrm{Age}^{2}$ & & $\begin{array}{l}-0.000 \\
(0.000)\end{array}$ & $\begin{array}{c}0.000 * * * \\
(0.000)\end{array}$ \\
\hline School & & & $\begin{array}{c}1.371 * * * \\
(0.038)\end{array}$ \\
\hline Ln_restaurant & & & $\begin{array}{l}0.010 * * \\
(0.005)\end{array}$ \\
\hline Ln_McD & & & $\begin{array}{c}0.033^{* * *} \\
(0.006)\end{array}$ \\
\hline Ln_station & & & $\begin{array}{c}-0.042 * * * \\
(0.007)\end{array}$ \\
\hline Ln_hospital & & & $\begin{array}{c}-0.099 * * * \\
(0.006)\end{array}$ \\
\hline Five_circle & & & $\begin{array}{c}0.225^{* * * *} \\
(0.014)\end{array}$ \\
\hline Time fixed effect & Yes & Yes & Yes \\
\hline Region fixed effect & Yes & Yes & Yes \\
\hline Observations & 109,599 & 105,872 & 105,872 \\
\hline
\end{tabular}

\section{B. Data Screening by Propensity Score Matching}

At present, lianJia has a huge market share in the real estate transaction market in Beijing. In the data sample of LianJia and FangTianXia, the share of FangTianXia only accounts for $3.9 \%$ and the significant difference in the magnitude of this data will have a great impact on the regression results of this paper, that is, the basic characteristics of the two transaction samples have large differences and are not able to satisfy the assumption of common trends. In order to make the regression sample of LianJia and FangTianXia more compatible and try to avoid the problem of sample selection error as much as possible, this section will use the Propensity Score Matching (PSM) proposed by Rosenbaum and Rubin (1983) to match real-time transaction data in a ratio of $1: 5$ to overcome the above problems.

After the balance test and the joint support test, the matched samples obtained above are linearly regressed. The regression equation (2) is used for regression, that is, the location attribute elements are removed for regression on the basis of regression equation (1), so as to more accurately explore the impact of Internet real estate intermediary platform on house price transaction price.

$$
\text { a_price }=\beta_{10}+\beta_{1} X_{\mathrm{P}}+\beta_{2} L_{\mathrm{i}}+\beta_{3} A g e n c y_{1}+\beta_{4} M_{\mathrm{i}}+\beta_{5} D_{\mathrm{i}}+u_{\mathrm{i}}
$$

The regression results are shown in column (2) of Table III. Table III shows the impact of Internet real estate intermediary platforms on housing transaction prices. The results show that the coefficient of the mediator variable is still significantly negative. Compared with LianJia, the transaction price of FangTianXia is lower about 2390 yuan per square meter, which is basically the same as the coefficient before PSM. This result shows that after matching the two sets of data through the propensity score matching, the basic conclusion that the Internet platform can better control the real estate transaction premium problem can be basically verified compared with the traditional intermediary.

In order to further explore the impact of the Internet platform on housing transactions in response to policy shocks, after the benchmark regression, this paper further explores the impact of Internet real estate intermediary platforms on price in response to policy shocks. In this paper, the transaction data selected in the benchmark regression analysis is used to construct the PSM-DID model and the difference between the two groups of samples is eliminated as much as possible, so that the control group sample is used as the counterfactual result of the treatment group to explore the difference in price of Internet real estate intermediary platforms in the face of policy shock. Therefore, this paper constructs the regression equation (3) based on the above research. This article will first consider the October 2015, that is, the central bank's last interest rate cut in 2015 as a policy shock, Policyt value takes 1 when housing transaction data is after October 2015, otherwise 0 . At the same time, this paper also adds the time fixed effect $\mathrm{M}_{\mathrm{i}}$ and the urban area fixed effect $\mathrm{D}_{\mathrm{i}}$ to this DID model. The regression results are shown in column (3) of Table III. It can be seen that the coefficient of the policy variable is significantly positive, which indicates that the proposal of the central bank's interest rate cut policy has brought about a significant increase in the transaction price of the real estate market in Beijing. The coefficient of interaction between policy variables and mediator variables is significantly negative, which also shows that the Internet real estate intermediary platform can effectively restrain the rapid rise of the real estate market price to a certain extent in response to policy shocks.

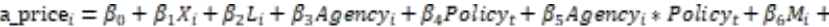
$\beta_{7} D_{1}+u_{p}$ 
TABLE || THE EFFECT OF INTERNET TRADING PLATFORM ON TRANSACTION

\begin{tabular}{|c|c|c|c|}
\hline Dependent Variable & $\begin{array}{c}\text { (1) } \\
a \_p r i c e\end{array}$ & $\begin{array}{c}\text { (2) } \\
a \_p r i c e\end{array}$ & $\begin{array}{c}\text { (3) } \\
a \_ \text {price }\end{array}$ \\
\hline Agency & $\begin{array}{c}-0.198 * * * \\
(0.021)\end{array}$ & $\begin{array}{c}-0.239 * * * \\
(0.021)\end{array}$ & $\begin{array}{c}-0.139 * * * \\
(0.033)\end{array}$ \\
\hline Policy & & & $\begin{array}{c}0.577 * * * \\
(0.042)\end{array}$ \\
\hline Agency*policy & & & $\begin{array}{c}0.146^{* * *} \\
(0.040) \\
\end{array}$ \\
\hline Control variables & $\mathrm{NO}$ & YES & YES \\
\hline Time fixed effect & YES & YES & YES \\
\hline Tegion fixed effect & YES & YES & YES \\
\hline Observations & 21,914 & 21,885 & 21,885 \\
\hline
\end{tabular}

\section{THE IMPACT OF INTERNET REAL ESTATE INTERMEDIARY PLATFORM ON THE VOLATILITY OF THE REAL ESTATE MARKET BASED ON THE SHOCK OF POLICY}

\section{A. Characterization of Trading Volatility in the Real Estate Market}

Compared with traditional intermediaries, Internet real estate intermediary platforms will generate less trading volatility when dealing with policy fluctuations. In order to verify the suppose, we first remove the influence of control variables on the transaction price. From the above empirical results, it can be seen that the control variables have a great impact on the real estate transaction price. Therefore, only by removing the influence of other factors on the transaction price of the real estate to obtain the volatility of the real estate transaction, we can better verify the impact of the type of Internet intermediary on the volatility of the transaction.

Therefore, this paper takes the data samples of the abovementioned transaction data of LianJia and FangTianXia according to the ratio of 1:5 to match the scores as object of study. Considering that the transaction data of FangTianXia is relatively small, it is difficult to accurately group the location elements into units. Therefore, this paper divides all the data into 12 districts in Beijing, according to the administrative districts of the city. At the same time, according to the trading month, it is divided into 24 groups. The housing transaction data of the same intermediary in the same month and administrative division is based on the average price of the housing transaction, and the regression is given by equation (4). We measure the degree of fluctuation in housing transactions by residual standard deviation obtained from regression results.

$$
\text { a_price }=\beta_{10}+\beta_{1} X_{\mathrm{P}}+\beta_{2} L_{\mathrm{i}}+u_{\mathrm{I}}
$$

${ }^{1}$ Considering that the number of samples is too small, it will cause a certain deviation to the regression analysis results. Statistical significance is only found when the number of samples in the regression statistics is greater than 30 . Therefore, we can make the regression result more accurate after obtaining the residual standard deviation of the transaction month, the city area and the intermediary unit by grouping and eliminating the residual standard deviation data of the number of internal transaction in one unit is less than 30 .

\section{B. Benchmark Regression method}

After obtaining this sample, the basic least squares regression equation is first studied to investigate the degree of fluctuations in the housing transactions of the two types of trading institutions. This paper uses equation (5) for regression:

Rmse $_{\text {itd }}=\beta_{0}+\beta_{1} \times A$ gency $y_{1}+\beta_{2} M_{1}+\beta_{3} D_{1}+u_{\text {ind }}$

Where $\mathrm{Rmse}_{\text {itd }}$ is the residual standard deviation obtained by the intermediaries $i$ in the housing transaction data of the urban area $d$ in the month $t$ after regression of equation (4) ${ }^{2}$ The regression results are shown in the first column of Table N.It can be seen that the coefficient of the mediator variable is negative. Compared with the mean value of the residual standard deviation of 0.764 , the Internet real estate

intermediary platform has slowed down about $37.3 \%$ of the transaction fluctuation to some extent. Therefore, the hypothesis proposed in this paper can be basically verified, that is, compared with the traditional intermediary, the Internet real estate intermediary platform will generate less transaction fluctuations when dealing with policy shocks.

\section{The Impact of Internet Real Estate Intermediary Platform on Trading Volatility based on Policy Shock}

In the context of the major policy of central bank interest rate cuts, this paper explores the extent to which Internet real estate intermediary platforms will be more effective in responding to policy shocks. Therefore, this paper will build the following DID model based on the regression equation (5), as shown in equation (6). The same with the PSM-DID model above, this paper also considers October 2015 as a policy shock. When the housing transaction data is after October 2015, we take the value of Policy 1 ; otherwise 0 . At the same time, this paper also adds the time fixed effect $\mathrm{M}_{\mathrm{i}}$ and the urban area fixed effect $\mathrm{D}_{\mathrm{i}}$ to the DID model.

$$
\left.{ }^{(6)}\right)^{B}
$$

Rmse $e_{\text {itd }}=\beta_{0}+\beta_{1} A_{\text {gency }}+\beta_{2}$ Policyt $+\beta_{3} A_{\text {gency }} *$ Policy $+\beta_{4} M_{1}+\beta_{5} D_{1}+$ unit

First, regression is performed according to the regression equation (4) to obtain the residual standard deviation data, then the data is used to regress the equation (6) and the obtained results are shown in the second column of Table IV. The regression results show that the coefficient of the policy variable is positive and significant, which is consistent with our speculation that the policy of the central bank to cut interest rates will result in a significant increase in the price volatility of the real estate market. We can see that the coefficient of the cross-variable Agency*Policy of the mediation variable and the policy variable is significantly negative, although the significance is not very high, the hypothesis of this paper can be basically verified, that is, in the face of policy shock, compared with traditional intermediaries, the new Internet real estate intermediary platform can effectively reduce the trading fluctuations in the real estate market.

TABLE IV THE IMPACT OF INTERNET REAL ESTATE INTERMEDIARY Platform On Housing TRAding Volatility DURING POLICY SHOCKS

\begin{tabular}{c|c|c}
\hline \multirow{4}{*}{$\begin{array}{c}\text { Dependent } \\
\text { Variable }\end{array}$} & $(1)$ & (2) \\
\cline { 2 - 3 } & Rmse & Rmse \\
\hline
\end{tabular}

${ }^{2}$ Since the missing variables will have a certain impact on the price of the house, the residual standard deviation will be biased to some extent. 


\begin{tabular}{|c|c|c|}
\hline Mean_Rmse & 0.764 & 0.764 \\
\hline Agency & $\begin{array}{c}-0.285 * * * \\
(0.068)\end{array}$ & $\begin{array}{l}-0.076 \\
(0.073)\end{array}$ \\
\hline Policy & & $\begin{array}{c}0.783 * * * \\
(0.188)\end{array}$ \\
\hline Agency*Policy & & $\begin{array}{c}-0.317 * * * \\
(0.113)\end{array}$ \\
\hline Time fixed effect & YES & YES \\
\hline $\begin{array}{c}\text { Urban area fixed } \\
\text { effect }\end{array}$ & YES & YES \\
\hline Observations & 160 & 160 \\
\hline
\end{tabular}

\section{ROBUST TEST}

\section{A. Introduction of Another Policy Shock Point}

In the above study, this paper uses the fifth central bank interest rate cut on October 24, 2015 as a policy shock point, the central bank has five interest rate cuts in 2015 and the previous few times will also affect the transaction price and volatility of the real estate market. In order to reduce the bias caused by endogeneity as much as possible, this paper uses the fourth interest rate cut by the central bank on August 25, 2015 as another policy shock in the difference-in-differences model on the basis of equation (3) and equation (6) to make the regression results more robust. Therefore, we construct regression equation (7) and regression equation (8).

a_price $=\beta_{10}+\beta_{1} X_{1}+\beta_{2}$ Agency $+\beta_{3}$ Policy $_{\mathrm{t}}+\beta_{4}$ Agency $*$ Policy + $\beta_{5}$ Policy ${ }_{\mathrm{t}}^{\prime}+\beta_{\mathrm{i}}$ Agency $*$ Policy ${ }_{\mathrm{t}}^{\prime}+\beta_{\mathrm{R}} M_{\mathrm{P}}+\beta_{\mathrm{B}} D_{\mathrm{L}}+u_{\mathrm{P}}$ (7)

Rmse $_{\text {ind }}=\beta_{3}+\beta_{1}$ Agency $+\beta_{2}$ Policy $_{t}+\beta_{3}$ Agency $*$ Policy $_{t}+$ $\beta_{4}$ Policy $_{\mathrm{t}}^{\prime}+\beta_{5}$ Agency $*$ Policy ${ }_{\mathrm{t}}^{\prime}+\beta_{\mathrm{i}} M_{\mathrm{i}}+\beta_{7} D_{\mathrm{i}}+u_{\text {itad }}$

$$
\text { (8) }
$$

Policy' ${ }_{t}$ is another policy shock, that is, Central bank cut interest rate policy on August 25, 2015. Policy' ${ }_{t}$ takes the value 1 when the housing transaction data is after August, otherwise 0 . The regression results are shown in Table $V$. It can be seen from the results in the table that the cross-term coefficients of both are negative when we introduce another interest rate cut policy as a policy shock, but this can further prove the robustness of the conclusion. From the regression results, it can be seen that when the fourth interest rate cut is introduced as a policy shock, the size and significance of the coefficient of the policy variable and its interaction term are weaker than the policy shock point of the fifth interest rate cut. On the one hand, this is due to the fact that the sample is too small when the fourth interest rate cut is taken as a policy shock. On the other hand, the fifth rate cut is also added into the model as a policy shock, which will further weaken the effect of the policy shock.

\section{B. Excluding the Impact of Previous Policy Shocks on Regression Results}

The research data used in this paper is real-time transaction data from 2015 to 2016. As mentioned in the previous article, the central bank lowered the deposit and loan benchmark interest rate five times and the deposit reserve ratio five times during 2015. Each downgrade has had a positive impact on the
Beijing real estate market but we only selected the fifth interest rate cuts as a policy shock point. Therefore, in order to exclude the impact of the first four interest rate cuts on the overall regression results, this paper takes the data from August 2015 to March 2016 as a sample, and re-runs the regression operation (3), operation (5) and operation (6). The results are shown in columns 1 and 2 of Table $V$ I. It can be seen that after excluding the influence of the previous policy shocks, the coefficient of the intermediate variable in the benchmark regression and the coefficient of the cross term in the difference-in-differences model are significantly negative, which further proves the robustness of the conclusion.

TABLE $\bigvee \mid$ MEASURING THE IMPACT OF INTERNET REAL Estate INTERMEDIARY PLATFORMS ON HOUSING TRANSACTION VOLATILITY AFTER EXCLUDING THE IMPACT OF THE PREVIOUS POLICY SHOCKS

\begin{tabular}{|c|c|c|}
\hline Dependent Variable & $\begin{array}{c}\text { (1) } \\
\text { a_price }\end{array}$ & $\begin{array}{c}\text { (2) } \\
\text { Rmse }\end{array}$ \\
\hline Mean_Rmse & & 0.764 \\
\hline agency & $\begin{array}{c}-0.125^{* * *} \\
(0.049)\end{array}$ & $\begin{array}{l}-0.069 \\
(0.117)\end{array}$ \\
\hline Policy’ & $\begin{array}{c}0.155^{* * *} \\
(0.034)\end{array}$ & $\begin{array}{l}0.123 * \\
(0.072)\end{array}$ \\
\hline agency*policy' & $\begin{array}{l}-0.028 \\
(0.065)\end{array}$ & $\begin{array}{l}-0.014 \\
(0.126)\end{array}$ \\
\hline Policy & $\begin{array}{c}0.422 * * * \\
(0.043)\end{array}$ & $\begin{array}{c}0.661 \text { *** } \\
(0.186)\end{array}$ \\
\hline agency*policy & $\begin{array}{c}-0.131 * * * \\
(0.049)\end{array}$ & $\begin{array}{c}-0.310 * * * \\
(0.114)\end{array}$ \\
\hline Control variables & YES & \\
\hline Time fixed effect & YES & YES \\
\hline Region fixed effect & YES & YES \\
\hline Observations & 21885 & 160 \\
\hline
\end{tabular}

TABle $V$ Introducing ANOther Policy Shock Point to Measure the IMPACT OF INTERNET REAL ESTATE INTERMEDIARY PLATFORM ON HOUSING

\begin{tabular}{|c|c|c|c|c|}
\hline $\begin{array}{c}\text { Dependent } \\
\text { Variable }\end{array}$ & $\begin{array}{c}\text { (1) } \\
\text { a_price }\end{array}$ & $\begin{array}{c}\text { (2) } \\
\text { a_price }\end{array}$ & $\begin{array}{c}\text { (3) } \\
\text { Rmse }\end{array}$ & $\begin{array}{c}\text { (4) } \\
\text { Rmse }\end{array}$ \\
\hline Mean_Rmse & & & 0.996 & 0.996 \\
\hline agency & $\begin{array}{c}-0.266^{* * *} \\
(0.023)\end{array}$ & $\begin{array}{c}-0.176 * * * \\
(0.044)\end{array}$ & $\begin{array}{c}-0.317 * * * \\
(0.080)\end{array}$ & $\begin{array}{l}-0.057 \\
(0.076)\end{array}$ \\
\hline Policy & & $\begin{array}{c}0.458 * * * \\
(0.046)\end{array}$ & & $\begin{array}{c}0.701 * * * \\
(0.183)\end{array}$ \\
\hline \multirow[t]{2}{*}{ agency*policy } & & $\begin{array}{c}-0.111 * * \\
(0.049)\end{array}$ & & $\begin{array}{c}-0.323 * * * \\
(0.116) \\
\end{array}$ \\
\hline & $(0.014)$ & $(0.014)$ & & \\
\hline Control variables & YES & YES & & \\
\hline Time fixed effect & YES & YES & YES & YES \\
\hline $\begin{array}{c}\text { Region fixed } \\
\text { effect }\end{array}$ & YES & YES & YES & YES \\
\hline Observations & 16701 & 16701 & 121 & 121 \\
\hline
\end{tabular}
of $1 \%, 5 \%$, and $10 \%$, respectively. 


\section{CONCLUSIONS AND DISCUSSIONS}

Based on the analysis of Beijing real estate transaction data from 2015 to 2016, this paper finds that the Internet real estate intermediary platform has an important impact on the healthy operation of the real estate market. From the perspective of price and price fluctuations, the difference-in- differences method, PSM-DID model and related robustness tests show that the Internet real estate intermediary platform has a positive effect on the healthy operation of the real estate market. Compared with traditional intermediaries, the intermediary model of internet can reduce the unit price of housing transactions and control the premium of the real estate market to a certain extent. In response to the policy shock of the central bank's interest rate cuts, the Internet real estate intermediary platform can better avoid the fluctuation of transactions and ease the price distortion to a certain extent compared with the traditional intermediary. After screening the data samples by propensity score matching, it is found that the Internet real estate intermediary platform also has inhibition effects on the overheating of house price growth in response to policy shocks. These effects can have a positive impact on the healthy operation of the housing market and even the national economy.

From a realistic point of view, with the rapid development of Internet technology, it has established in-depth integration and connection with the development of various industries. From the perspective of information processing, the Internet can be seen as a new type of intermediary for information transparency. When the intermediary property of the Internet is fully exerted in the real estate market, the market will realize complete information transparency and openness, and the resource allocation of the real estate market will also reach the Pareto optimal state, so that the ideal real estate market will play an important role in promoting the healthy operation of the economic market.

\section{REFERENCES}

[1] Wei Yanqiu, Huang Xu. The fit, mode and prospect of Internet + real estate [J]. China real estate,2016(33):44-50.

[2] Yang liu, $\mathrm{Li} \mathrm{Li}, \mathrm{Wu}$ Ting. The expected impact and the volatility of China's real estate market [J]. Economics (quarterly), 2017(1):321-348.

[3] Xia Yang. Research and discussion on "Internet + " model of real estate industry [J]. China real estate,2015(13):60-63.

[4] Hu Wanyang, Zheng siqi, Wang rui. How big the premium of school district housing is: an empirical estimation using "different rights to rent and buy" and matching regression [J]. Economics (quarterly),2014,13(03):1195-1214.

[5] Guo Kesha. Demand and regulation mechanism of Chinese real estate market -- an analytical framework to deal with the relationship between government and market [J]. Management world,2017(02):97-108.

[6] Guo Jiatang, Luo Pinliang. Does the Internet promote China's total factor productivity? [J]. Management world,2016(10):34-49.

[7] Zhang Hao, Li Zhongfei, Deng Baijun. Policy uncertainty, macro impact and housing price fluctuation -- an empirical analysis based on LSTVAR model [J]. Financial research,2015(10):32-47.

[8] Deng Fumin, Liang Xuedong. Macro-economy, government regulation and real estate market development -- a review of policy regulation and the development of China's real estate market [J]. Economic research,2012,47(12):152-155.
[9] Zhao Yang, Zhang Yishan, Zhao Wensheng. Research on the relationship between the real estate market and consumer consumption and economic growth -- an empirical analysis based on the wealth effect of the real estate market from 1994 to 2011 [J]. Economic science, 2011(06):30-41.

[10] Hou Hanpo, He Mingke, Pang Yi, Zheng Guoliang. Analysis of Internet resource attribute and economic impact [J]. Management world,2010(03):176-177.

[11] Tan Zhengxun, Wang cong. Research on financial stability effect of credit expansion and housing price fluctuation in China -- perspective of dynamic stochastic general equilibrium model [J]. Financial research,2011(08):57-71.

[12] Bar-Isaac H, Gavazza A. Brokers' Contractual Arrangements in the Manhattan Residential Rental Market[J]. Mpra Paper, 2013:73-82.

[13] Levitt S D, Syverson C. Market Distortions when Agents are Better Informed: The Value of Information in Real Estate Transactions[J]. Nber Working Papers, 2005, 90(90):599-611.

[14] Shi L, Tapia C. The Disciplining Effect of Concern for Referrals: Evidence from Real Estate Agents[J]. Real Estate Economics, 2016, 44(2).

[15] Xu Y, Zhang Q, Zheng S. The rising demand for subway after private driving restriction: Evidence from Beijing's housing market[J]. Regional Science \& Urban Economics, 2015, 54:28-37.

[16] Yavas A. Impossibility of a competitive equilibrium in the real estate brokerage industry[J]. Journal of Real Estate Research, 2001, 21(3): 187-200.

[17] Rutherford RC, Springer TM, Yavas A. Conflicts between principals and agents: evidence from residential brokerage[J]. Journal of Financial Economics, 2005, 76(3): 627-665.

[18] Chen M X, Wu M. The Value of Reputation in Trade: Evidence from Alibaba[J]. Working Papers, 2016.

[19] Levin J. The Economics of Internet Markets[J]. Discussion Papers, 2011.

[20] Dinerstein M, Einav L, Levin J, et al. Consumer Price Search and Platform Design in Internet Commerce[J]. Nber Working Papers, 2014.

[21] Chesnes M, Jin G Z. Direct-to-Consumer Advertising and Online Search[J]. Social Science Electronic Publishing, 2016.

[22] Boik A, Greenstein S M, Prince J. The Empirical Economics of Online Attention[J]. Social Science Electronic Publishing, 2016.

[23] Shi L, Tapia C. The Disciplining Effect of Concern for Referrals: Evidence from Real Estate Agents[J]. Real Estate Economics, 2016, 44(2).

[24] Nwogugu M. Issues in disintermediation in the housing sector[J]. Applied Mathematics \& Computation, 2007, 186(2):1054-1064.

[25] Li L H, Wang C. Real estate agency in China in the information age[J]. Property Management, 2006, 24(24):47-61.

[26] Bakos J Y. Reducing Buyer Search Costs: Implications for Electronic Marketplaces[J]. Management Science, 1997, 43(12):1676-1692.

[27] Harold Gee. Residential Real Estate Data on the Internet: Benefits and Limitations[J]. Journal of Business \& Finance Librarianship, 2010, 15(2):104-122.

[28] Tse R Y C, Webb J R. The Effectiveness of a Web Strategy for Real Estate Brokerage[J]. Journal of Real Estate Literature, 2002, 10.

[29] Pereira P. Do lower search costs reduce prices and price dispersion?[J]. Information Economics \& Policy, 2005, 17(1):61-72.

[30] Yang T L T, Trefzger J W, Sherman L F. A Microeconomic Study of Commercial Real Estate Brokerage Firms[J]. Journal of Real Estate Research, 1997, 13(2):177-194.

[31] Anglin P M. The Contribution of Buyer Brokers[J]. Journal of Housing Economics, 1997, 6(3):277-292.

[32] Clayton, Jim. 1996. "Rational Expectations, Market Fundamentals and Housing Price Volatility." Journal of Real Estate Economics 24 (4): $441-47$ 